\title{
Article
}

\section{Involvement of Virus-Induced Interferon Production in IgG Autoantibody-Mediated Anemia}

\author{
Sarah Legrain ${ }^{1,+}{ }^{+}$, Dan Su ${ }^{1}$, Mélanie Gaignage ${ }^{1}$, Cor Breukel ${ }^{2}$, Jill Claassens ${ }^{2}$, Conny Brouwers ${ }^{2}$, \\ Margot M. Linssen ${ }^{2}$, Shozo Izui ${ }^{3}$, J. Sjef Verbeek ${ }^{2, \ddagger}$ and Jean-Paul Coutelier ${ }^{1, *}$
}

1 Unit of Experimental Medicine, de Duve Institute, Université Catholique de Louvain, 1200 Bruxelles, Belgium; sarah.legrain.phd@gmail.com (S.L.); sudan20072007@yahoo.com (D.S.); melanie.gaignage@uclouvain.be (M.G.)

2 Department of Human Genetics, Leiden University Medical Center, 2300 RC Leiden, The Netherlands; C.Breukel@lumc.nl (C.B.); J.W.C.Claassens@lumc.nl (J.C.); C.M.Brouwers@lumc.nl (C.B.); M.M.L.Linssen@lumc.nl (M.M.L.); j.s.verbeek@toin.ac.jp (J.S.V.)

3 Department of Pathology and Immunology, Centre Médical Universitaire, University of Geneva, 41211 Geneva, Switzerland; shozo.izui@gmail.com

* Correspondence: jean-paul.coutelier@uclouvain.be; Tel.: +32-2-764-7437; Fax: +32-2-764-7430

+ Present address: 54b rue d'Eghezée, 5060 Auvelais, Belgium.

$\ddagger$ Present address: Department of Biomedical Engineering, Toin University of Yokohama, Yokohama 225-8503, Japan.

check for

updates

Citation: Legrain, S.; Su, D.;

Gaignage, M.; Breukel, C.; Claassens,

J.; Brouwers, C.; Linssen, M.M.; Izui,

S.; Verbeek, J.S.; Coutelier, J.-P.

Involvement of Virus-Induced Interferon Production in IgG

Autoantibody-Mediated Anemia. Int.

J. Mol. Sci. 2021, 22, 9027. https://

doi.org/10.3390/ijms22169027

Academic Editor: Markus Biburger

Received: 29 June 2021

Accepted: 17 August 2021

Published: 21 August 2021

Publisher's Note: MDPI stays neutral with regard to jurisdictional claims in published maps and institutional affiliations.

Copyright: (c) 2021 by the authors. Licensee MDPI, Basel, Switzerland. This article is an open access article distributed under the terms and conditions of the Creative Commons Attribution (CC BY) license (https:/ / creativecommons.org/licenses/by/ $4.0 /)$.

\begin{abstract}
Infection with viruses, such as the lactate dehydrogenase-elevating virus (LDV), is known to trigger the onset of autoimmune anemia through the enhancement of the phagocytosis of autoantibodyopsonized erythrocytes by activated macrophages. Type I interferon receptor-deficient mice show enhanced anemia, which suggests a protective effect of these cytokines, partly through the control of type II interferon production. The development of anemia requires the expression of Fc $\gamma$ receptors $(\mathrm{Fc} \gamma \mathrm{R}) \mathrm{I}$, III, and IV. Whereas LDV infection decreases Fc $\gamma$ R III expression, it enhances Fc $\gamma \mathrm{R}$ I and IV expression in wild-type animals. The LDV-associated increase in the expression of Fc $\gamma \mathrm{R}$ I and IV is largely reduced in type I interferon receptor-deficient mice, through both type II interferon-dependent and -independent mechanisms. Thus, the regulation of the expression of Fc $\gamma$ R I and IV, but not III, by interferons may partly explain the exacerbating effect of LDV infection on anemia that results from the enhanced phagocytosis of IgG autoantibody-opsonized erythrocytes.
\end{abstract}

Keywords: Fc receptors; lactate dehydrogenase-elevating virus; autoimmune anemia; interferon

\section{Introduction}

Mouse infection with the lactate dehydrogenase-elevating virus (LDV) has been shown to exacerbate autoimmune diseases, such as antibody-mediated anemia [1,2] and thrombocytopenia [3,4]. This effect of LDV infection can be explained by the enhanced phagocytic activity of macrophages [1,3], thus leading to the engulfment and destruction of opsonized cells in response to the macrophage activation, which is mostly triggered by the gammainterferon (IFN- $\gamma$ ) secreted by natural killer cells upon infection [5]. Thus, LDV provides a useful experimental model to study the role of viral infections and, more precisely, the impact of their triggered cytokine secretion in the pathogenesis of autoantibody-mediated blood autoimmune diseases, such as immune thrombocytopenic purpura and hemolytic anemia.

The respective roles of Fc receptors (FcRs) and antibody isotypes in the phagocytosis of opsonized erythrocytes have been extensively analyzed in uninfected animals through the use of a large panel of anti-red blood cell antibody switch variants and mice deficient in one or several FcRs for IgG $\left(F_{c} \gamma R\right)$ [6-9]. These studies indicate that all anti-erythrocyte antibody isotypes can be pathogenic at different levels, depending on their affinity and dose as well as on their interactions with the various activating FcRs and with complement. Interestingly, all activating Fc $\gamma$ Rs (Fc $\gamma R$ I, Fc $\gamma$ R III, and Fc $\gamma R$ IV) can mediate the 
phagocytosis of erythrocytes opsonized by IgG2a, a major autoantibody isotype produced in mouse experimental models [10-12], leading to anemia [9]. The increased capacity of macrophages from LDV-infected mice to bind and ingest opsonized targets was explained by a virus-induced enhancement of Fc $\gamma$ R expression on these cells [13], but this has never been directly demonstrated. Thus, the present study was performed to analyze the effects of LDV infection on the expression of all activating Fc $\gamma$ Rs, their involvement in the exacerbated phagocytic activity, and the resulting anemia triggered by infection.

\section{Results}

\subsection{Role of Type I and Type II IFNs in Red Blood Cell (RBC) Phagocytosis in LDV-Infected Mice}

To demonstrate the effect of viral infection on the establishment of autoimmune hemolytic anemia, 34-3C anti-RBC IgG2a mAb was injected into LDV-infected mice. The administration of $50 \mu \mathrm{g}$ of this antibody to wild-type (WT) C57BL/ 6 mice induced moderate anemia after 4 and 5 days compared to WT animals treated with the control IgG2a (Figure 1A), and LDV infection worsened the anemia developed by 34-3C-treated mice (Figure $1 \mathrm{~A}, p=0.0005$ and $p<0.0081$, respectively). Interestingly, type I IFNs, which are produced early on in the course of infection [14], seem to protect mice from severe anemia, as LDV-infected IFNAR KO $129 / \mathrm{Sv}$ mice that received a large amount of 34-3C mAb $(350 \mu \mathrm{g})$ showed decreased survival compared to the control WT 129/Sv mice (Figure 1B, $p=0.009$ ). This correlated with higher anemia in type I IFN-deficient animals 4 days after the antibody infusion (Figure 1C, $p=0.0286$, compared to the WT 129/Sv counterparts) and was prevented with a blockade of IFN- $\gamma$ signaling in IFNAR KO mice (Figure 1D, $p=0.0286$ ). The ex vivo erythrophagocytosis of CMFDA-labeled and 34-3C opsonized RBCs by peritoneal macrophages isolated from infected IFNAR KO mice was increased compared to macrophages from WT 129/Sv mice (Figure 1E, $p=0.0002$ ). In contrast, a blockade of IFN- $\gamma$ signaling reduced ex vivo erythrophagocytosis by WT and IFNAR KO macrophages (Figure 1E, $p=0.0015$ and $p=0.0003$, respectively), which corroborates the in vivo data. Altogether, these results suggest a protective role of type I IFNs in the development of LDV-exacerbated autoimmune anemia thwarted by type II IFN.

\subsection{Involvement of $F c \gamma R$ s in In Vivo and Ex Vivo LDV-Exacerbated Erythrophagocytosis}

The hematocrits of LDV-infected WT mice and mice deficient in Fc $\gamma$ Rs were compared 4 days after the administration of a moderate dose of 34-3C mAb (Figure 2A,B). In uninfected animals, the absence of Fc $\gamma$ R III (Fc $\gamma$ R I/III, Fc $\gamma$ R II/III/IV, and Fc $\gamma$ R I/II/III/IV $\mathrm{KO}$ mice) led to strongly reduced anemia compared to the WT animals (Figure 2A). In addition, a minor role of $\mathrm{Fc} \gamma \mathrm{R}$ I was suggested by a limited reduction in the disease in animals deficient in this receptor. Finally, LDV-infected Fc $\gamma \mathrm{R}$ KO mice were completely resistant to 34-3C-induced hemolytic anemia (Figure 2A, $p<0.0001$ ), whereas the depletion of the complement protein $\mathrm{C} 3$ through the administration of cobra venom factor (CVF) did not decrease the development of anemia in LDV-infected 34-3C-treated WT mice (Figure S1). These results suggest a C3-independent but Fc $\gamma$ R-dependent mechanism of RBC phagocytosis on LDV infection. The anemia developed in LDV-infected Fc $\gamma$ R I, Fc $\gamma$ R I/III, and Fc $\mathrm{R}$ II/III/IV KO mice was partially inhibited compared to the anemia in WT animals, but not as strongly as in Fc $\gamma \mathrm{R}$ I/II/III/IV mice (Figure 2A). In addition, the anemia of 34-3C-treated Fc $\gamma$ R III KO mice increased after LDV infection but did not reach the same severity as the anemia of their WT counterparts (Figure 2B, $p=0.0364$ ). Together, these results point to the involvement of all activating $\mathrm{F}_{\mathrm{C}} \gamma \mathrm{Rs}$ in virally exacerbated anemia induced by the 34-3C autoantibody.

The ex vivo erythrophagocytosis of CMFDA-stained 34-3C-opsonized RBCs by peritoneal macrophages harvested from LDV-infected C57BL/ 6 mice increased compared to their counterparts obtained from mock-infected controls (Figure 2C, middle vs. left panel, $p=0.0047)$, and this enhanced erythrophagocytic activity was abolished in macrophages harvested from infected Fc $\gamma \mathrm{RI} / \mathrm{II} / \mathrm{III} / \mathrm{IV}$ quadruple $\mathrm{KO}$ mice (Figure 2C, middle vs. right 
panel, $p=0.0006)$. These in vitro results are in agreement with our in vivo data, demonstrating that in the absence of all Fc $\gamma$ Rs, erythrophagocytosis is abolished. 

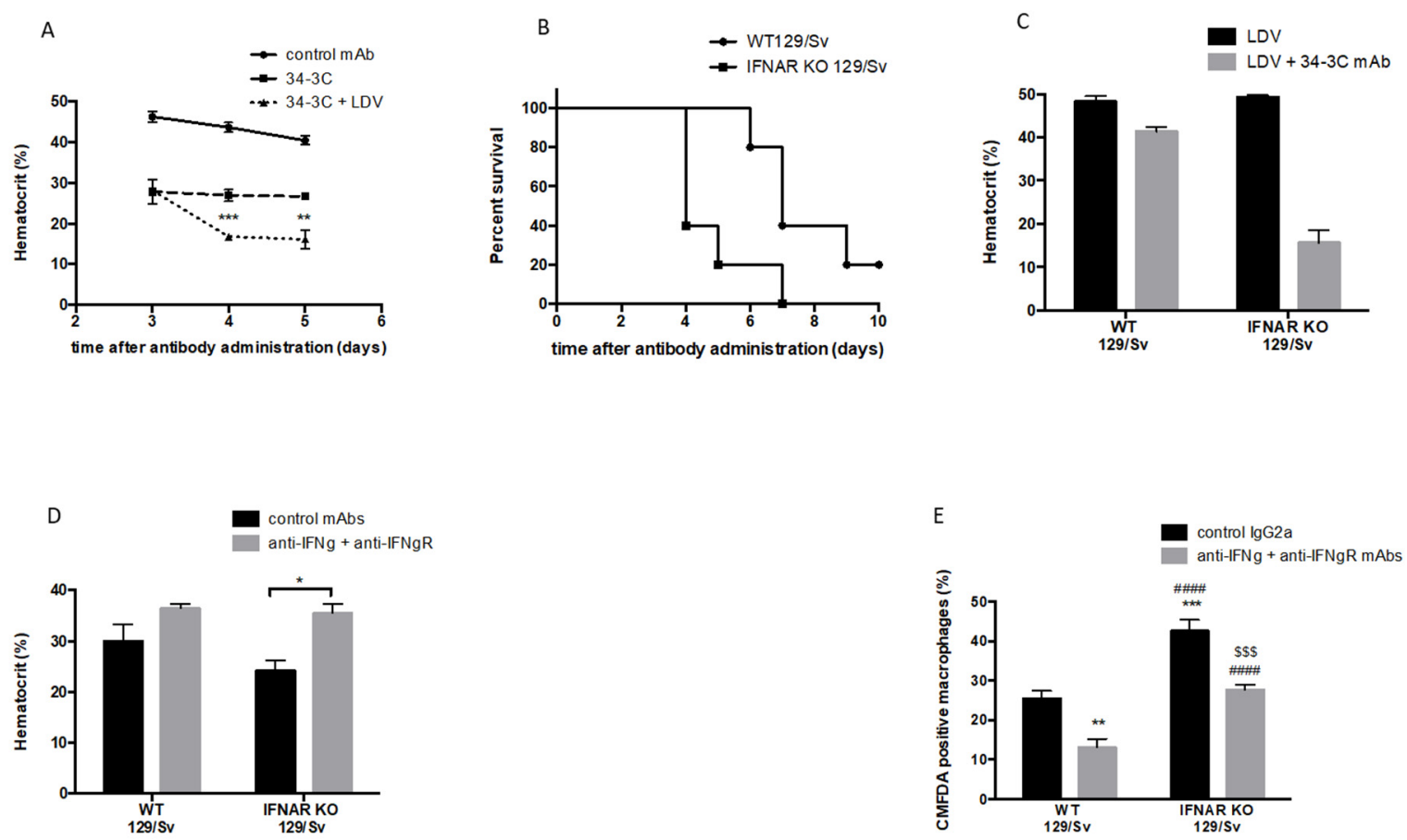

Figure 1. Role of type I and type II IFNs in anemia and ex vivo erythrophagocytosis in LDV-infected mice. (A) Hematocrits in groups of 6 to 8 C57BL/ 6 mice pooled from 2 independent experiments at different times after administration of $50 \mu \mathrm{g}$ 34-3C IgG2a mAb or A6202F4M control mAb. LDV infection occurred one day before mAb administration. (B) Survival of 10 129/Sv or IFNAR KO-infected mice after administration of $350 \mu \mathrm{g}$ 34-3C anti-RBC mAb. (C) Hematocrit in groups of WT $129 / \mathrm{Sv}$ or IFNAR KO mice challenged with $50 \mu \mathrm{g}$ of 34-3C IgG2a mAb or A6202F4M control mAb. Hematocrit were measured 4 days after LDV infection. (D) Hematocrits after administration of $50 \mu \mathrm{g} 34-3 \mathrm{C}$ IgG2a mAb to groups of $4129 / \mathrm{Sv}$ or IFNAR KO-infected mice treated with or without IFN- $\gamma$ and IFN- $\gamma$ R-blocking antibodies (300 $\mu$ g one day before LDV infection, $1 \mathrm{mg} 3 \mathrm{~h}$ after infection, followed by a dose of $1 \mathrm{mg}$ every 2 days). (E) Ex vivo erythrophagocytosis of 34-3Copsonized RBCs by macrophages of 9 to 11 129/Sv or IFNAR KO-infected mice pooled from 2 independent experiments and treated with or without IFN- $\gamma$ and IFN- $\gamma$ R-blocking antibodies (300 $\mu \mathrm{g}$ one day before LDV infection, $500 \mu \mathrm{g} 3 \mathrm{~h}$ after infection). ${ }^{*} p<0.05,{ }^{* *} p<0.01,{ }^{* *} p<0.001,{ }^{*}$ compared to infected $129 / \mathrm{Sv} ; \$ \$ \$$ compared to anti-IFN $\gamma$-treated infected $129 / \mathrm{Sv}$; \#\#\# compared to IFNAR KO. The results are shown as the means $\pm \mathrm{SEM}$.

\subsection{Modification of Fc $\gamma$ Receptor Expression by LDV Infection}

The expression of activating Fc $\gamma$ Rs was measured through flow cytometry on CD11b ${ }^{+}$ $\mathrm{F} 4 / 80^{+}$peritoneal macrophages. $\mathrm{LDV}$ infection induced an increase in the population of macrophages expressing Fc $\gamma \mathrm{R}$ I and Fc $\gamma \mathrm{R}$ IV one day after infection (Figure $3 \mathrm{~A}, p=0.0286$ and Figure S2A; Figure 3D, $p=0.0286$, and Figure S2C, respectively). This correlated with a strong increase in the mRNA expression of both receptors (Figure $3 \mathrm{E}, p=0.0062$ and Figure 3G, $p=0.0092$, respectively) one day post-infection. In contrast, LDV slightly decreased both the number of peritoneal macrophages expressing Fc $\gamma \mathrm{R} \mathrm{III}$ and the intensity of Fc $\gamma$ R III expression in these cells (Figure 3B, $p=0.0286$ and Figure 3C, $p=0.0286$, respectively, and Figure S2B). This decrease in Fc $\gamma \mathrm{R}$ III membrane protein expression correlated with a decreased expression of Fc $\gamma \mathrm{R}$ III mRNA (Figure 3F, $p=0.0038$ ). In contrast, the expression of CR3 mRNA did not change in the LDV-infected mice compared to the mock-infected animals (Figure $3 \mathrm{H}$ ). 

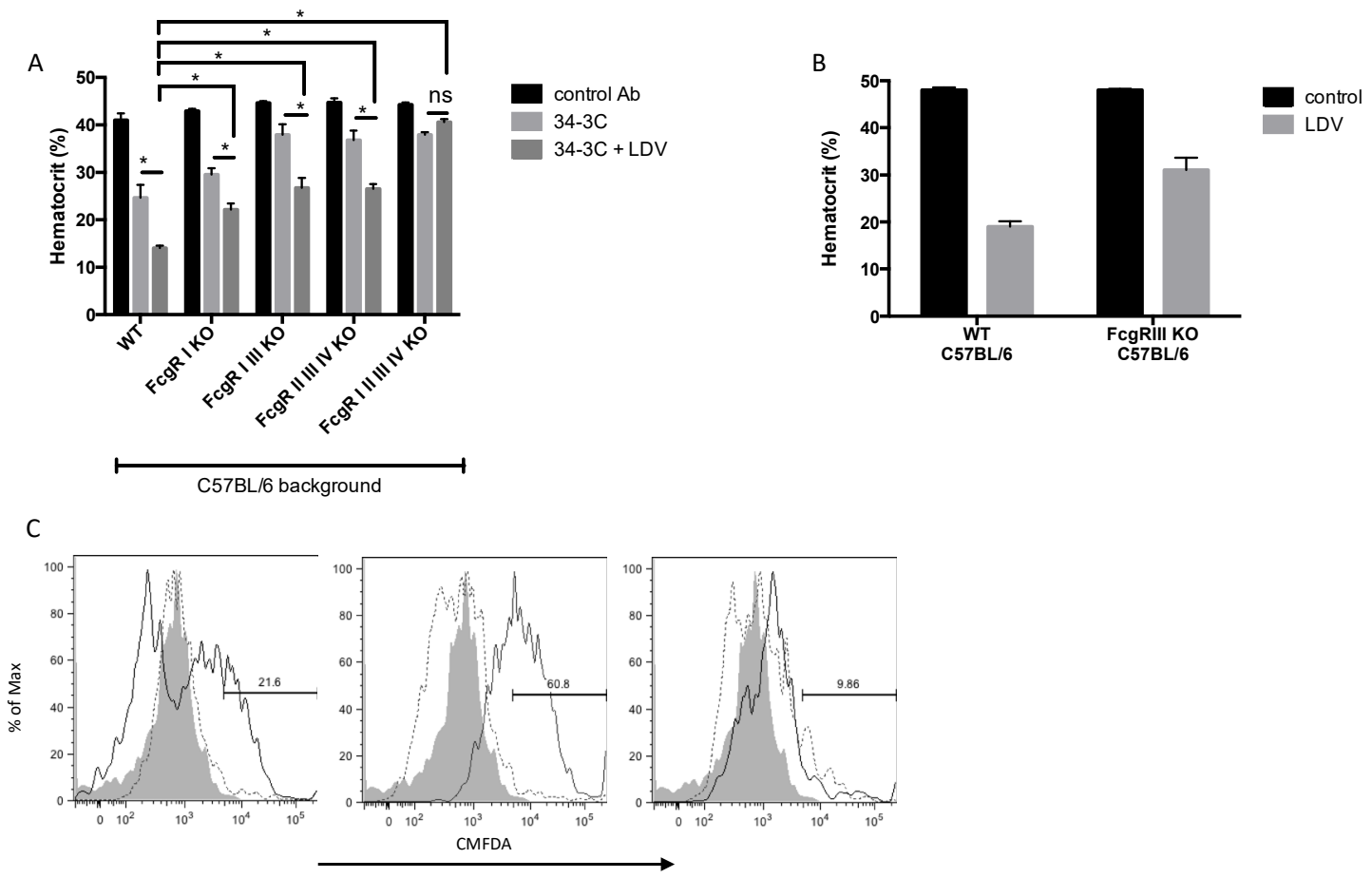

Figure 2. Involvement of $\mathrm{Fc}_{\mathrm{C}} \gamma$ receptors in LDV-exacerbated in vivo and ex vivo erythrophagocytosis. (A,B) Hematocrits of C57BL/6, Fc $\gamma$ R I KO, Fc $\gamma$ R I/III KO, Fc $\gamma$ R II/III/IV KO, Fc $\gamma$ R I/II/III/IV KO (A), and Fc $\gamma$ R III KO (B) mice, 4 days after administration of $50 \mu \mathrm{g}$ of $34-3 \mathrm{C}$ mAb. LDV infection was performed one day before the antibody challenge. The results are representative of at least 2 experiments and shown as the means $\pm \mathrm{SEM}$, ). ${ }^{*} p<0.05$. (C) Ex vivo erythrophagocytosis of non-opsonized (dashed line) or 34-3C-opsonized (plain line) CMFDA-stained RBCs by macrophages isolated from (left panel) mock-infected C57BL/6, (middle panel) LDV-infected C57BL/6, and (right panel) LDV-infected Fc $\gamma \mathrm{R} \mathrm{I/II/III/IV}$ $\mathrm{KO}$ (grey: fluorescence of macrophages without RBC incubation). The results are representative of at least 2 independent experiments.
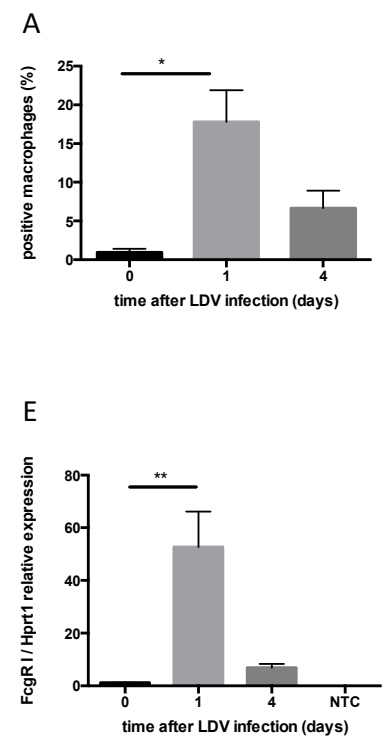
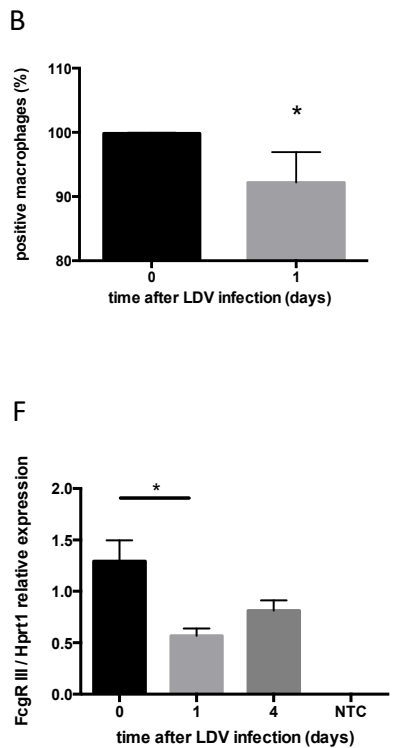
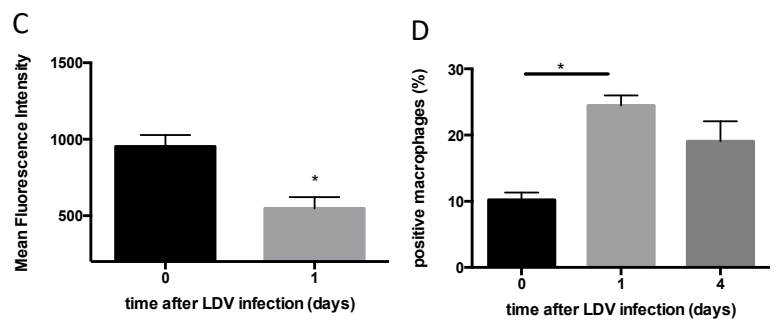

G

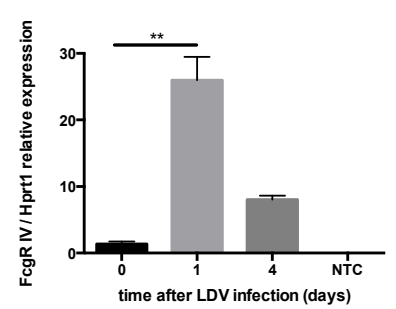

H

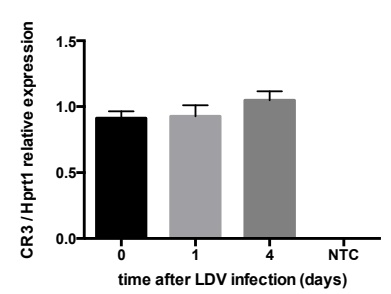

Figure 3. Modulation of activating Fc $\gamma$ receptors and of CR3 expression after LDV infection. (A-D) The CD11b+ F4/80+ peritoneal macrophages of 4 mock- or LDV-infected C57BL/ 6 were stained with either anti-Fc $\gamma \mathrm{R} \mathrm{I} \mathrm{(A),} \mathrm{anti-Fc} \gamma \mathrm{R} \mathrm{III} \mathrm{(B,C),}$ or anti-Fc $\gamma$ R IV (D) antibodies. (E-H) Fc $\gamma(\mathbf{E}-\mathbf{G})$ and C3 (H) receptor gene expression in CD11b+ F4/80+ peritoneal macrophages from groups of 4 mock- or LDV-infected C57BL/ 6 were assessed by RT-qPCR. The results are shown as the means \pm SEM. NTC: negative control. ${ }^{*} p<0.05,{ }^{* *} p<0.01$. 


\subsection{Effect of Type I and Type II IFNs on Fc $\gamma R$ Expression}

IFNAR KO mice were used to determine the role of type I IFNs in the modulation of Fc $\gamma$ R expression after LDV infection. The expression of Fc $\gamma$ R I mRNA strongly decreased in LDV-infected IFNAR KO mice compared to the expression of Fc $\gamma \mathrm{R}$ I mRNA in the WT counterparts (Figure 4A, $p=0.0286$ ). Treatment with a cocktail of anti-IFN- $\gamma$ and anti-IFN- $\gamma \mathrm{R}$ mAbs resulted in a moderate increase in the expression of Fc $\gamma \mathrm{R}$ I in the WT (Figure $4 \mathrm{~A}, p=0.086$ ) but not the IFNAR KO mice. The expression of Fc $\gamma \mathrm{R}$ IV mRNA was also reduced in infected IFNAR KO mice compared to their WT counterparts (Figure 4C). However, in contrast to its enhancing effect on Fc $\gamma$ R I mRNA expression, the IFN- $\gamma$ blockade slightly decreased Fc $\gamma$ R IV mRNA expression in both WT and IFNAR KO mice (Figure 4C). Decreased Fc $\gamma$ R III mRNA expression was prevented with the blockade of IFN- $\gamma$ signaling (Figure $4 \mathrm{~B}, p=0.0286$ ).

A

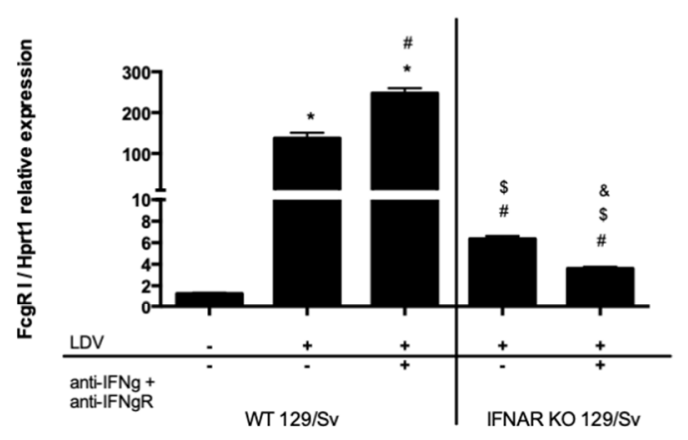

C

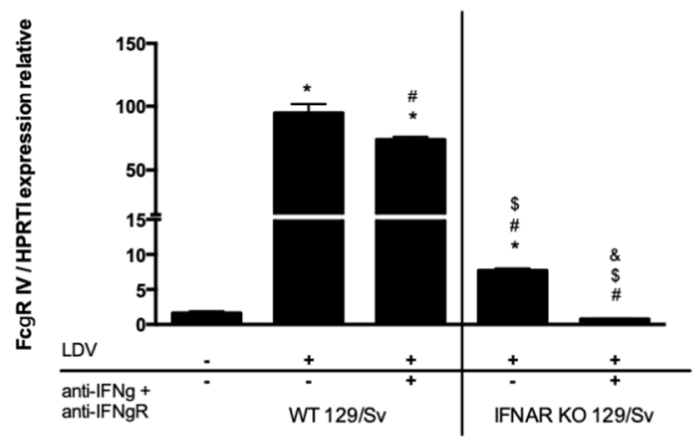

B

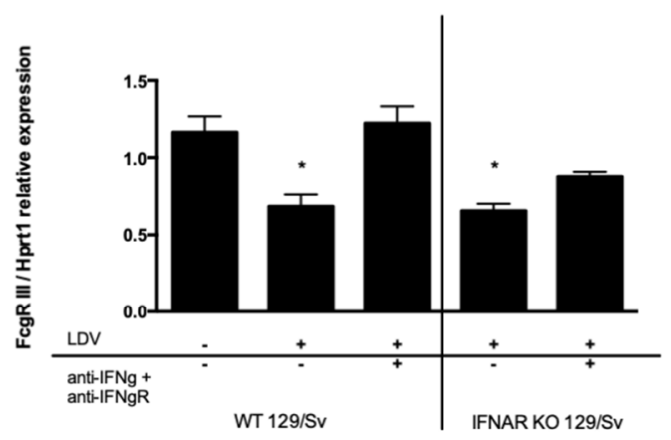

Figure 4. Role of type I and type II IFNs in Fc $\gamma$ receptor expression in peritoneal macrophages of LDV-infected mice. The expressions of Fc $\gamma \mathrm{R}$ I (A), Fc $\gamma \mathrm{R}$ III (B), and Fc $\gamma \mathrm{R}$ IV (C) were measured by RT-qPCR in macrophages isolated from groups of 4 129/Sv or IFNAR KO mice 1 day after LDV infection. * compared to control 129/Sv; \# compared to infected 129/Sv; $\$$ compared to infected $129 / \mathrm{Sv}$ treated with IFN- $\gamma$ and IFN- $\gamma$ R-blocking antibodies. \& compared to infected IFNAR KO treated with IFN- $\gamma$ and IFN- $\gamma$ R-blocking antibodies. The results are shown as the means \pm SEM.

\section{Discussion}

Strong evidence has been reported that LDV exacerbates diseases, such as thrombocytopenia and hemolytic anemia by increasing the uptake of target cells by macrophages [1-4]. Although platelets or erythrocytes are most often ingested after opsonization with IgG autoantibodies, LDV infection alone may also result in antibody-independent thrombocytopenia [15]. Other mouse viruses, including the mouse hepatitis virus (MHV) [3] and the lymphocytic choriomeningitis virus [16], have also been reported to induce macrophage activation, leading to the enhanced destruction of opsonized platelets or erythrocytes. Such a pathogenic mechanism may thus contribute to human autoimmune diseases following 
infection with common viruses, such as immune thrombocytopenic purpura and hemolytic anemia, which have also been recently reported after infection with SARS-CoV-2 [17-19].

Viral infections are known to trigger the secretion of several IFN types, including IFN- $\gamma$, which is secreted by NK cells after LDV and MHV infection $[5,20]$ and which mediates most observed macrophage activation. Thus, IFN- $\gamma$ plays a major role in the exacerbation of antibody-mediated thrombocytopenia and anemia induced by viruses, such as LDV [2-4,21], as well as in enhanced sensibility to endotoxin shock [22]. In contrast, we found that type I IFNs protect against autoantibody-mediated macrophage uptake and the resulting anemia. A similar protective effect against LDV-induced sensitization to endotoxin shock was also reported [22]. Since type I IFNs modulate LDV-induced IFN- $\gamma$ secretion [23], it may be postulated that their protective effect is mostly indirect. However, an additional direct regulating effect on macrophages could not be excluded.

As expected, the pathogenicity of an IgG2a anti-erythrocyte autoantibody, the most frequent isotype found in experimental models of anemia, depends on Fc $\gamma$ receptor expression in macrophages. It was reported that the induction of severe anemia by a high dose of an IgG2a anti-erythrocyte autoantibody is dependent on Fc $\gamma R$ I and Fc $\gamma$ R IV, whereas the induction of mild anemia by a low dose of the same antibody is dependent on FcgR III [9]. Using a panel of Fc $\gamma \mathrm{R} \mathrm{KO}$ mice, we found that the absence of Fc $\gamma \mathrm{R}$ I led to reduced anemia induced by IgG autoantibodies in LDV-infected animals, and that merely the expression of Fc $\gamma R$ I allowed for the development of anemia, although it was less severe compared to the disease induced in WT mice receiving the same autoantibody. Moreover, severe anemia triggered by autoantibody administration to LDV-infected mice appeared to also depend on the concomitant expression of both Fc $\gamma$ R III and Fc $\gamma$ R IV. Therefore, it could be postulated that the increased uptake of opsonized erythrocytes by macrophages from LDV-infected mice might correlate with an increased expression of activating Fc $\gamma$ Rs. This was the case for Fc $\gamma \mathrm{R}$ I and Fc $\gamma \mathrm{R}$ IV. In contrast, macrophage Fc $\gamma \mathrm{R}$ III expression decreased after LDV infection, although its functional involvement can be demonstrated. This observation, confirming the role of Fc $\gamma \mathrm{R} \mathrm{III} \mathrm{in} \mathrm{autoantibody-induced} \mathrm{anemia} \mathrm{[24],} \mathrm{can}$ possibly be explained by an increased affinity of this receptor for IgG2a Ab; however, this would need to be confirmed through ligand-binding assays. Such a higher affinity of the IgG2a isotype has been reported for Fc $\gamma$ R III of C57BL/ 6 mice, compared with IgG2c-the equivalent isotype of these animals-although both IgG2a and IgG2c strongly reacted with Fc $\gamma$ R I, Fc $\gamma$ R III and Fc $\gamma$ R IV [25]. Another possible explanation is that Fc $\gamma$ R expression in peritoneal macrophages differs from that in Kupfer cells, the main cell type involved in the phagocytosis of IgG-opsonized erythrocytes in the liver [26]. Thus, the severe anemia triggered by autoantibody administration to LDV-infected mice appeared to depend on the concomitant expression of all three activating receptors: Fc $\gamma$ R I, Fc $\gamma$ R III, and Fc $\gamma$ R IV. Fc $\gamma$ R I expression was previously shown to be induced by IFN- $\gamma$ [27]. However, the strong increase in Fc $\gamma R$ I expression observed in WT mice after LDV infection was not suppressed by treatment with neutralizing anti-IFN- $\gamma \mathrm{mAb}$, whereas enhanced Fc $\gamma \mathrm{R}$ IV expression only moderately decreased with this treatment. This might be due to an activating effect of other cytokines produced in response to LDV infection, or to an insufficient neutralizing effect of the mAb due to the large amounts of IFN- $\gamma$ resulting from this infection. In addition, type I IFNs appear to also contribute to the enhanced expression of both Fc $\gamma R$ $\mathrm{I}$ and $\mathrm{F} c \gamma \mathrm{R}$ IV expression after LDV infection, since this expression was largely reduced in type I IFN receptor KO mice. Moreover, in these animals, the neutralization of IFN- $\gamma$ further reduced the enhancement in Fc $\gamma \mathrm{R}$ I expression by LDV infection and completely abolished the enhancement in Fc $\gamma$ R IV expression by LDV infection, suggesting that type I and II IFNs are concomitantly involved in this effect of the virus.

Therefore, the enhancement in $\mathrm{F}_{\mathrm{c}} \gamma \mathrm{R}$ I and $\mathrm{Fc} \gamma \mathrm{R}$ IV expression resulting from type I and II IFN secretion might play an important role in the severe anemia induced in infected animals. However, since type I IFN appears to induce opposite effects on Fc $\gamma$ R expression and RBC destruction, mechanisms other than $\mathrm{F}_{\gamma} \gamma \mathrm{R}$ modulation might also play a role in the exacerbating effect of the virus on autoantibody-mediated anemia. 


\section{Materials and Methods}

\subsection{Mice and Virus}

Specific pathogen-free C57BL/6, IFN- $\alpha$ / BR $/$ - (IFNAR KO) (PMID 8009221), and WT $129 / \mathrm{Sv}$ mice were bred at the Ludwig Institute for Cancer Research (Brussels, Belgium) by G. Warnier. All the mice used were aged between 8 and 12 weeks old. The project was approved by the local commission for animal care.

The mice were infected with an intraperitoneal injection of approximately $2 \times 10^{7} 50 \%$ infectious doses ( $\mathrm{ID}_{50}$ ) of LDV (Riley strain; ATCC, Manassas, VA) in $500 \mu \mathrm{L}$ saline.

Fc $\gamma$ R I KO (Fcgr1 ${ }^{\text {tm1Jsv }}$, MGI 2664927), Fc $\gamma$ R III KO (Fcgr3 ${ }^{\text {tm1Jsv }}$, MGI:1861924), Fc $\gamma$ R II/III/IV KO [28], and Fc $\gamma$ R I/II/III/IV KO mice [29] on the C57BL/ 6 background were kindly provided by the laboratory of Sjef Verbeek in the Netherlands. The mice were mated at the De Duve Institute by S. Legrain, and the pups were genotyped using the appropriate primers.

\subsection{Antibodies and Drugs}

The CRL-2024 anti-IFN- $\gamma$ receptor, F3 anti-IFN- $\gamma$, 34-3C anti-red blood cells (RBCs), IgG2a mAbs, and 2.4G2 anti-Fc $\gamma \mathrm{R}$ IIb/III IgG2b mAb (gamma block) were purified on protein $\mathrm{G}$ sepharose beads from hybridoma cultures. PE anti-mouse CD64 mAb (Fc $\gamma \mathrm{R}$ I), PE isotype control, PE anti-mouse F4/80, APC anti-mouse F4/80, PerCP anti-mouse CD11b mAbs, and Alexa 647 anti-mouse Fc $\gamma$ R IV mAbs were purchased from Biolegend (San Diego, CA, USA). PE anti-mouse CD16 (Fc $\gamma$ R III) was purchased from R\&D Systems (Minneapolis, MN, USA). Normal hamster IgG (eBioscience, San Diego, CA, USA) was used as a control isotype. Cobra Venom Factor (CVF; Quidel Corporation, San Diego, CA, USA) was used at a rate of $4 \mathrm{U} /$ mouse.

\subsection{Isolation and Culture of Peritoneal Cells}

Resident peritoneal macrophages were harvested by washing the peritoneal cavity with ice-cold PBS supplemented with 5\% fetal bovine serum (FBS, Gibco, Life Technologies, Grand Isle, NY, USA), $50 \mathrm{U} / \mathrm{mL}$ penicillin G, $50 \mu \mathrm{g} / \mathrm{mL}$ streptomycin (Gibco, Life Technologies), and $2 \mathrm{mM}$ EDTA (Sigma Aldrich, St. Louis, MO, USA). The cells were washed, resuspended in Iscove's Modified Dulbecco's Medium (IMDM, Gibco Life Technologies) supplemented with $10 \%$ FBS, non-essential amino acids, $50 \mathrm{U} / \mathrm{mL}$ penicillin $\mathrm{G}$, and $50 \mu \mathrm{g} / \mathrm{mL}$ streptomycin, and plated in a 6-well tissue culture plate (Corning Inc., Corning, NY, USA). After $2 \mathrm{~h}$ of incubation at $37^{\circ} \mathrm{C}$ and $7 \% \mathrm{CO}_{2}$, the non-adherent cells were washed away and the adherent peritoneal macrophages were processed.

\subsection{Type I and Type II IFN Stimulation}

Adherent peritoneal macrophages were cultured in IMDM, supplemented as described above, containing $100 \mathrm{U} / \mathrm{mL}$ of either IFN- $\alpha$, IFN- $\beta$ (Biolegend, San Diego, CA, USA), or both for $24 \mathrm{~h}$. When indicated, $20 \mathrm{U} / \mathrm{mL}$ of IFN- $\gamma$ (Biolegend, San Diego, CA, USA) was added for $48 \mathrm{~h}$ following the type I IFN stimulation.

\subsection{Hematocrit}

Blood was collected from the retro-orbital plexus of the anesthetized mice, and the hematocrits were measured after the centrifugation of heparinized blood in a Hettich Haematokrit centrifuge (Tuttlingen, Germany).

\subsection{Flow Cytometry}

Flow cytometry analysis was performed as follows: peritoneal adhering cells were incubated with 2.4G2 (gamma block) $\mathrm{mAb}$ prior to incubation with either PE anti-mouse Fc $\gamma$ R I, PE anti-mouse Fc $\gamma$ R III, or Alexa 647 anti-mouse Fc $\gamma$ R IV antibodies. PerCP antimouse CD11b and APC or PE anti-mouse F4/80 staining were performed simultaneously to label the macrophages. Fluorescence was acquired with an LSR Fortessa flow cytometer 
(Becton Dickinson, Franklin Lakes, NJ, USA) and analyzed using FlowJo Software 9.8.1 (Tree Star Inc., Ashland, OR, USA).

\subsection{Gene Expression Analysis}

The total RNA was isolated from peritoneal adhering cells using a Reliaprep RNA Cell Miniprep System from the Promega Corporation (Fitchburg, WI, USA). RNA purity was measured using a Nanodrop 6000, and RNA integrity was assessed with $1 \%$ agarose gel electrophoresis. Then, $1 \mu \mathrm{g}$ of total RNA was reverse-transcribed using RevertAid H minus Reverse Transcriptase (Thermo Scientific, Waltham, MA, USA) and oligo dT as a primer, according to the manufacturer's instructions.

Gene expression was measured by RT-qPCR with an Eco Real-Time thermocycler (Illumina, San Diego, CA, USA), using a Core Kit for SYBR Green I (Eurogentec, Liege, Belgium). The primers for Fc $\gamma R$ I [21], Fc $\gamma R$ III, Fc $\gamma R$ IV [22], and CR3 [23] are described elsewhere. HPRT1 gene expression was used as a reference gene (forward: $5^{\prime}$ TAATCACGACGCTGGGACTG- ${ }^{\prime}$, and reverse: $5^{\prime}$-GTTGGGCTTACCTCACTGCT- $3^{\prime}$ ). The HPRT1 primers were designed using a Primer-BLAST (NCBI, Bethesda, MD, USA) and were validated for stability among 6 references genes using GeNorm software (Biogazelle, Zwijnaarde, Belgium). The ratios between the genes of interest and HPRT1 expression were calculated using the Eco Real-Time qPCR software (Illumina, San Diego, CA, USA).

\subsection{Ex Vivo Erythrophagocytosis}

A total of $40 \times 10^{6}$ control or 34-3C-opsonized CMDFA-labeled RBCs were incubated for $2 \mathrm{~h}$ at $37^{\circ} \mathrm{C}$ with $3 \times 10^{6}$ adherent peritoneal macrophages. After $2 \mathrm{~h}$, nonphagocytosed RBCs were washed away twice with $1 \mathrm{~mL}$ of RT $1 \times$ PBS. The adherent peritoneal macrophages were lifted up in $1 \mathrm{~mL}$ of ice-cold $1 \times$ PBS-BSA $0.5 \%$ supplemented with $2 \mathrm{mM}$ EDTA $+1 \%$ FBS and gentle cell scraping. Sticking RBCs were lysed by osmotic shock (ACK lysis buffer) before resuspension in HCF $+1 \%$ FBS. Dying cells were then stained with TO-PRO ${ }^{\circledR}-3$ (Life Technologies, Grand Isle, NY, USA) before acquisition on an LSR Fortessa flow cytometer (Becton Dickinson, Franklin Lakes, NJ, USA).

\subsection{Statistical Analysis}

The results are expressed as the means \pm the standard error of the mean (SEM). When appropriate, Mann-Whitney and Kruskal-Wallis tests were performed using Prism 6 (La Jolla, CA, USA).

Supplementary Materials: The following are available online at https://www.mdpi.com/article/10 $.3390 / \mathrm{ijms} 22169027 / \mathrm{s} 1$.

Author Contributions: Conceptualization, S.L., S.I., J.S.V. and J.-P.C.; data curation, D.S.; formal analysis, S.L., S.I., J.S.V. and J.-P.C.; funding acquisition, J.-P.C.; investigation, S.L. and M.G.; methodology, C.B. (Cor Breukel), J.C., C.B. (Conny Brouwers), and M.M.L.; project administration, J.-P.C.; resources, C.B. (Cor Breukel), J.C., C.B. (Conny Brouwers), and M.M.L.; writing-original draft, S.L.; writing-review and editing, D.S., M.G., C.B. (Cor Breukel), J.C., C.B. (Conny Brouwers), M.M.L., S.I,, J.S.V. and J.-P.C. All authors have read and agreed to the published version of the manuscript.

Funding: This work was supported by the Fonds National de la Recherche Scientifique (FNRS) and the "Actions de recherche concertées" from the Communauté française de Belgique, Direction de la Recherche Scientifique, Belgium. S.L. is a Ph.D. fellow with the FRIA and J.-P.C. is a research director with the FNRS.

Institutional Review Board Statement: The study was conducted according to the guidelines of the Declaration of Helsinki, and approved by the Institutional Ethics Committee of the Université catholique de Louvain (protocol 2013-14/UCL/MD/008 and approved in May 2013).

Informed Consent Statement: Not applicable.

Data Availability Statement: Data available on request. 
Acknowledgments: The authors are indebted to J. Van Snick for helpful discussions, and Paméla Chéou for expert technical assistance.

Conflicts of Interest: The authors declare no conflict of interest.

\section{References}

1. Meite, M.; Léonard, S.; Idrissi, M.E.A.E.; Izui, S.; Masson, P.L.; Coutelier, J.-P. Exacerbation of Autoantibody-Mediated Hemolytic Anemia by Viral Infection. J. Virol. 2000, 74, 6045-6049. [CrossRef]

2. Coutelier, J.; Detalle, L.; Musaji, A.; Meite, M.; Izui, S. Two-Step Mechanism of Virus-induced Autoimmune Hemolytic Anemia. Ann. N. Y. Acad. Sci. 2007, 1109, 151-157. [CrossRef]

3. Musaji, A.; Cormont, F.; Thirion, G.; Cambiaso, C.L.; Coutelier, J.-P. Exacerbation of autoantibody-mediated thrombocytopenic purpura by infection with mouse viruses. Blood 2004, 104, 2102-2106. [CrossRef]

4. Musaji, A.; Meite, M.; Detalle, L.; Franquin, S.; Cormont, F.; Préat, V.; Izui, S.; Coutelier, J.-P. Enhancement of autoantibody pathogenicity by viral infections in mouse models of anemia and thrombocytopenia. Autoimmun. Rev. 2005, 4, 247-252. [CrossRef] [PubMed]

5. Markine-Goriaynoff, D.; Hulhoven, X.; Cambiaso, C.L.; Monteyne, P.; Briet, T.; Gonzalez, M.-D.; Coulie, P.; Coutelier, J.-P. Natural killer cell activation after infection with lactate dehydrogenase-elevating virus. J. Gen. Virol. 2002, 83, 2709-2716. [CrossRef] [PubMed]

6. Fossati-Jimack, L.; Reininger, L.; Chicheportiche, Y.; Clynes, R.; Ravetch, J.V.; Honjo, T.; Izui, S. High Pathogenic Potential of Low-Affinity Autoantibodies in Experimental Autoimmune Hemolytic Anemia. J. Exp. Med. 1999, 190, 1689-1696. [CrossRef] [PubMed]

7. Fossati-Jimack, L.; Ioan-Facsinay, A.; Reininger, L.; Chicheportiche, Y.; Watanabe, N.; Saito, T.; Hofhuis, F.M.A.; Izui, S. Markedly different pathogenicity of four immunoglobulin $\mathrm{G}$ isotype-switch variants of an antierythrocyte autoantibody is based on their capacity to interact in vivo with the low-affinity Fcy receptor III. J. Exp. Med. 2000, 191, 1293-1302. [CrossRef]

8. Azeredo da Silveira, S.; Kikuchi, S.; Fossati-Jimack, L.; Moll, T.; Saito, T.; Verbeek, J.S.; Botto, M. Complement activation selectively potentiates the pathogenicity of the IgG2b and IgG3 isotypes of a high affinity anti-erythrocyte autoatibody. J. Exp. Med. 2002, 195, 665-672. [CrossRef]

9. Baudino, L.C.; Nimmerjahn, F.; Da Silveira, S.A.; Martinez-Soria, E.; Saito, T.; Carroll, M.; Ravetch, J.V.; Verbeek, J.S.; Izui, S Differential Contribution of Three Activating IgG Fc Receptors (Fc $\gamma$ RI, Fc $\gamma$ RIII, and Fc $\gamma$ RIV) to IgG2a- and IgG2b-Induced Autoimmune Hemolytic Anemia in Mice. J. Immunol. 2008, 180, 1948-1953. [CrossRef]

10. Scott, B.B.; Sadigh, S.; Stow, M.; Mageed, R.A.K.; Andrew, E.M.; Maini, R.N. Molecular mechanisms resulting in pathogenic anti-mouse erythrocyte antibodies in New Zealand black mice. Clin. Exp. Immunol. 2008, 93, 26-33. [CrossRef]

11. Vella, A.T.; Pfau, C.J. The Presence of an Anti-Erythrocyte Autoantibody in C3HeB/FeJ mice after Lymphocytic Choriomeningitis Virus Infection. Autoimmunity 1991, 9, 319-329. [CrossRef]

12. Mazza, G.; Day, M.J.; Barker, R.N.; Corato, A.; Elson, C.J. Quantitation of Erythrocyte-Bound IgG Subclass Autoantibodies in Murine Autoimmune Haemolytic Anaemia. Autoimmunity 1996, 23, 245-255. [CrossRef]

13. Lussenhop, N.; Holmes, B.; Cafruny, W.A.; Plagemann, P.G.W. Acute Infection of Mice with Lactate Dehydrogenase-elevating Virus Enhances Fc and Complement Receptor Activity of Peritoneal Macrophages. J. Gen. Virol. 1982, 61, 25-32. [CrossRef] [PubMed]

14. Dubuy, H.; Baron, S.; Uhlendorf, C.; Johnson, M.L. Role of Interferon in Murine Lactic Dehydrogenase Virus Infection, In Vivo and In Vitro. Infect. Immun. 1973, 8, 977-984. [CrossRef]

15. Su, D.; Musaji, A.; Legrain, S.; Detalle, L.; Van Der Kaa, J.; Verbeek, J.S.; Ryffel, B.; Coutelier, J.-P. Antibody-Independent Thrombocytopenia in Lactate Dehydrogenase-Elevating Virus-Infected Mice. J. Virol. 2012, 86, 12414-12416. [CrossRef] [PubMed]

16. El-Azami-El-Idrissi, M.; Franquin, S.; Day, M.J.; Mazza, G.; Elson, C.J.; Préat, V.; Pfau, C.J.; Coutelier, J.-P. Distinct Host-Dependent Pathogenic Mechanisms Leading to a Similar Clinical Anemia After Infection with Lymphocytic Choriomeningitis Virus. Exp. Biol. Med. 2005, 230, 865-871. [CrossRef]

17. Lazarian, G.; Quinquenel, A.; Bellal, M.; Siavellis, J.; Jacquy, C.; Re, D.; Merabet, F.; Mekinian, A.; Braun, T.; Damaj, G.; et al. Autoimmune hemolytic anemia associated with Covid-19 infection. Br. J. Haematol. 2020, 190, 29-31. [CrossRef] [PubMed]

18. Lopez, C.; Kim, J.; Pandey, A.; Huang, T.; De Loughery, T.G. Simultaneous onset of COVID-19 and autoimmune hemolytic anemia. Br. J. Haematol. 2020. [CrossRef] [PubMed]

19. Lippi, G.; Plebani, M.; Henry, B.M. Thrombocytopenia is associated with severe coronavirus disease 2019 (COVID-19) infections: A meta-analysis. Clin. Chim. Acta 2020, 506, 145-148. [CrossRef] [PubMed]

20. Thirion, G.; Coutelier, J.-P. Production of protective gamma interferon by natural killer cells during early mouse hepatitis virus infection. J. Gen. Virol. 2009, 90, 442-447. [CrossRef]

21. Musaji, A.; Markine-Goriaynoff, D.; Franquin, S.; Thirion, G.; Phuong, T.L.T.; Coutelier, J.-P. Gamma-Interferon Involvement in the Pathogenesis of Lactate Dehydrogenase-Elevating Virus Infection. Adv. Exp. Med. Biol. 2006, 581, 439-443.

22. Le-Thi-Phuong, T.; Dumoutier, L.; Renauld, J.-C.; Van Snick, J.; Coutelier, J.-P. Divergent roles of interferons in the sensitization to endotoxin shock by lactate dehydrogenase-elevating virus. Intern. Immunol. 2007, 19, 1303-1311. [CrossRef]

23. Le-Thi-Phuong, T.; Thirion, G.; Coutelier, J.-P. Distinct gamma interferon-production pathways in mice infected with lactate dehydrogenase-elevating virus. J. Gen. Virol. 2007, 88, 3063-3066. [CrossRef] 
24. Ravetch, J.V.; Bolland, S. IgG Fc receptors. Annu. Rev. Immunol. 2001, 19, 275-290. [CrossRef]

25. Shinde, P.; Howie, H.L.; Stegmann, T.C.; Hay, A.M.; Waterman, H.R.; Szittner, Z.; Bentlage, A.E.H.; Kapp, L.; LissenbergThunnissen, S.N.; Dekkers, G.; et al. IgG Subclass Determines Suppression Versus Enhancement of Humoral Alloimmunity to Kell RBC Antigens in Mice. Front. Immunol. 2020, 11, 1516. [CrossRef] [PubMed]

26. Berney, T.; Shibata, T.; Merino, R.; Chicheportiche, Y.; Kindler, V.; Vassalli, P.; Izui, S. Murine autoimmune hemolytic anemia resulting from Fc gamma receptor-mediated erythrophagocytosis: Protection by erythropoietin but not by interleukin-3, and aggravation by granulocyte-macrophage colony-stimulating factor. Blood 1992, 79, 2960-2964. [CrossRef]

27. Pearse, R.N.; Feinman, R.; Shuai, K.; Darnell, J.E.; Ravetch, J.V. Interferon gamma-induced transcription of the high-affinity Fc receptor for IgG requires assembly of a complex that includes the 91-kDa subunit of transcription factor ISGF3. Proc. Natl. Acad. Sci. USA 1993, 90, 4314-4318. [CrossRef] [PubMed]

28. Benonisson, H.; Sow, H.S.; Breukel, C.; Claassens, J.W.; Brouwers, C.; Linssen, M.M.; Redeker, A.; Fransen, M.F.; Van Hall, T.; Ossendorp, F.; et al. Fc $\gamma$ RI expression on macrophages is required for antibody-mediated tumor protection by cytomegalovirusbased vaccines. Oncotarget 2018, 9, 29392-29402. [CrossRef] [PubMed]

29. Fransen, M.F.; Benonisson, H.; Van Maren, W.W.; Sow, H.S.; Breukel, C.; Linssen, M.M.; Claassens, J.W.C.; Brouwers, C.; Van Der Kaa, J.; Camps, M.; et al. A Restricted Role for Fc $\gamma$ R in the Regulation of Adaptive Immunity. J. Immunol. 2018, 200, 2615-2626. [CrossRef] [PubMed] 